INTERNATIONAL JOURNAL OF

ARTIFICIAL INTELLIGENCE AND EMERGING

TECHNOLOGY

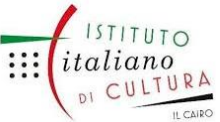

\title{
DEVELOPMENT OF GOLD AND SILVER PLATING SYSTEMS FOR METAL PRODUCTS AS ECO-FRIENDLY ALTERNATIVES
}

\author{
Muhammad Al-Awami MUHAMMAD
}

Metal Products and Ornaments Department, College of Applied Arts, Benha University, Egypt

\begin{abstract}
Many metal product surface treatment industries face many problems related to the application of environmental standards and the commitment to preserve them and the ability to use environmentally friendly alternatives, due to the lack of economic resources and the lack of technological development in finding appropriate solutions, reuse and recycling of wastes resulting from surface finishing operations in general and electroplating in general. Despite the availability of modern technology in some major industrial establishments, environmental alternatives have not entered into actual application in most of these establishments due to their weak effectiveness compared to the processes that are actually applied and which have great harm to different environments, especially processes that depend on cyanide in electroplating. Gold plating processes are also considered hey are widely used in covering metal products, especially jewellery, jewellery, tableware, utensils ... and others. Therefore, the use of non-cyanide environmental alternatives for gold and silver plating systems will reduce many pollutants that are harmful to different

environments of the product, especially industrial ones.
\end{abstract}

Keywords

Gold, Silver, Plating Systems, Metal Products, Eco-Friendly Alternatives.

\section{Introduction}

Pollution has become one of the environmental problems that have received the attention of states in the second half of the last century, and the fact is that pollution is an environmental phenomenon that has existed since people were found on the surface of the earth, as pollution is primarily human action, but it remained limited and did not reach the point of the problem, until The industry supported by technological superiority occupied the summit of the productive activities through which man sought to impose his control on his environment.

With the increase and breadth of these problems, they have become a direct or indirect factor in canceling or developing productive systems and many industrial processes. Therefore, human thought has tended to reduce the cases of pollution after the process of eliminating them completely became impossible due to the industrial revolution and the rapid development of technology without concern taking seriously the aspect of improving the environment and protecting it from the effects of pollution. And that this reduction process requires laying the foundations and global determinants to control cases of pollution and the creation of sophisticated and accurate scientific devices that can be used through their use to know the different cases of pollution.

In the manufacture of metal products, mechanical finishing processes such as sanding, grinding, and polishing do not contribute significantly to the generation of hazardous wastes such as chemical and electro-chemical processes. These processes are usually carried out in acidic or alkaline solutions, followed 


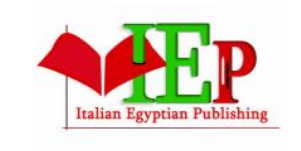

ISSN: $2735-4806$

\section{INTERNATIONAL JOURNAL OF \\ ARTIFICIAL INTELLIGENCE AND EMERGING \\ TECHNOLOGY}

VOLUME 1, ISSUE 1, 2018, 1-20.

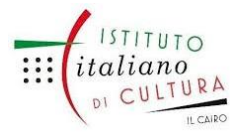

www.egyptfuture.org/ojs/

by water washing operations. The most common sources of hazardous waste are the disposal of washing water or spent solutions in sanitation.

The main pollutants of concern in the metal finishing industry are spent solutions that contain heavy metals and other toxic and harmful chemicals. Metal finishes handle these solutions in wastewater treatment systems designed to meet the requirements of the ATO (CWA) communications workers of America. These systems in turn generate solid and liquid wastes

Regulated under the provisions of the RCRA Resource Conservation and Recovery Act Air emissions from many metal finishes must be controlled using cleaning equipment. This can result in other waste that must be treated, disposed of, or recycled. Some of the treatment solutions used in metal finishing have a limited life, especially paint solutions by transfer or reduction. Dip off acids, detergents, and plating solutions with electricity. These processes produce concentrated waste. The surface treatment industry for metal products is concerned with pollution and waste resulting from all processes, especially those resulting from the use of four specific materials in coating processes:

1- The use of cadmium as a coating mineral. 2-Use chrome plating materials.

3- $\quad$ Use of cyanide-based electroplating solutions.

4- $\quad$ The use of a copper electroplating solution made of copper and formaldehyde salts.

The use of any of these materials has benefits and risks, especially the pollution prevention techniques that occur in Sections Three and Four. It is important to realize that the waste that is produced from the industrial process of SMUs requires wastewater treatment systems and air purification filters. But the most important thing is to use remedial processes. By its nature, "clean or environmentally friendly" (i.e. it has no or weak effect on the environment), thus significant progress can be made towards reducing the negative impacts on the environment.

\section{Results and Discussion}

1- The environment has become a powerful factor in canceling or developing productive systems and many industrial processes. Therefore, human thought has tended to reduce the cases of pollution resulting from technological development without paying attention to preserving the environment and protecting it from the effects of pollution.

2- $\quad$ The presence of any of the materials (solid, liquid, or gas) or polluting factors (or noise, radiation, heat or vibration) in the environment in a specific amount and for a period of time that may lead, directly or indirectly, to harm to humans and the living creatures in which they are found.

3- The sources of pollutants in the public or industrial environment must be identified by knowing their chemical, physical and biological composition, as well as the location and quantity of these pollutants during their release to the environment, in order to develop 


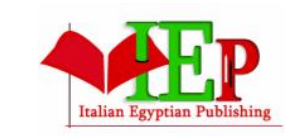

ISSN: $2735-4806$

\section{INTERNATIONAL JOURNAL OF \\ ARTIFICIAL INTELLIGENCE AND EMERGING \\ TECHNOLOGY}

VOLUME 1, ISSUE 1, 2018, $1-20$.

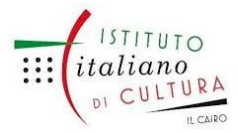

www.egyptfuture.org/ojs/

action plans to control pollution.

4- $\quad$ Failure to follow design methods to dispose of waste and waste and not to use environmentally friendly alternatives, and the industrial administration's interest in production only, without looking at other aspects, may have many negative effects on humans and the environment.

5- Production units and factories must follow specific and important controls such as: providing technical and technical personnel, conducting scientific research and specialized scientific studies that allow (choosing technical alternatives - reusing industrial products and waste - developing pollutant measurement devices), then raising awareness and raising the level of environmental awareness.

6- $\quad$ The metal product surface treatment and finishing industry with a wide range of operations that are carried out on metal parts and these units emit a variety of toxic compounds, such as hydrocarbon chlorate during solvent disinfection (degreasing) of metal parts; Harmful fumes, cyanides and heavy metals are also produced from electroplating processes.

7- The waste produced from the industrial processes of the metal surface treatment units needs water treatment systems, sanitation and air purification filters.

8- $\quad$ The sources of pollutants in the process of painting and treatment are multiple, including what is produced from filtering and washing solutions, spent solutions, or solutions spilled (wasted) on the ground.

9- Conventional systems for plating gold and silver use sodium and potassium cyanide in the formulation of solutions. It causes a lot of harm to humans, such as (sensitive to the skin and eyes, and it is very toxic).

10- $\quad$ - The strategy to reduce pollutants must be prepared taking into account some elements such as (identifying places or sources of Pollutants - Formulation and application of pollutant reduction measures - Analysis of all process operating parameters - Cost estimate $\cdots$

11- - The use of environmentally friendly alternatives to get rid of pollutants is an important method that has been used in the electroplating processes to improve and protect the industrial environment for this process.

12- $\quad$ 12- The non-cyanide alternative systems are characterized by many properties such as: Environmentally friendly, non-polluting, and with distinct layers of coating, as the resulting coating layers are shiny, hard and very flexible. With cyanide solutions, it has better resistance during operation, and it is also used to paint complex shapes easily.

13- - The cost of non-cyanide coatings is estimated to be about $12-15 \%$ higher than the current cyanide-based processes, and this is not a significant increase if environmental issues such 


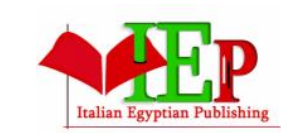

ISSN: $2735-4806$

\section{INTERNATIONAL JOURNAL OF \\ ARTIFICIAL INTELLIGENCE AND EMERGING \\ TECHNOLOGY}

VOLUME 1, ISSUE 1, 2018, 1-20.

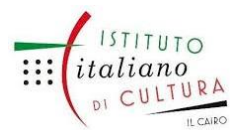

www.egyptfuture.org/ojs/

as the costs of recycling and waste treatment are taken into account.

14- - The main challenge of using non-cyanide alternatives it is keeping up with prices and lower stability compared to the cyanide-based systems that are still widely used in the manufacture of metal products, however they are already banned for all production processes, and the obviously increasing environmental requirements open the way for better alternatives in electroplating products.

\section{Recommendations}

1. Use cyanide-free systems, and minimize filtering.

2. Avoid coating with metals that affect the environment and people, such as cadmium and chromium.

3. Use water-wash systems after recycling and treating them rather than draining.

4. Reuse of some process solutions and solvents recovered from air pollution control systems.

5. Not to use substances that affects the ozone layer.

6. Treat silt sediments as dangerous pollutants, and reuse them if possible, provided they do not have emissions harmful to the environment.

\section{References}

1- Jean-Marie Bennett, The Reconciliation of Man and Nature / His translation. Mr. Muhammad Othman, The Scientist of Knowledge, No. (12), Al Siyasa Press, Kuwait, September (1974 AD), p. 21

2- Magdy Khalifeh Mohamed, Doctor, Environmental Design Standards and its Relation to the Competitiveness of the Egyptian Product, Faculty of Applied Arts, Helwan University, Ph.D., 2016.

3- Ghazi Ahmad Amer, The Industrial Environment Improvement and Methods for its Protection, Dar Tigris Press, Iraq, 2010, pp. 34-39

4- $\quad$ Alan blair- silver plating-(2011) 78th Universal Metal Finishing Guidebook-- Metal Finishing Magazine- Elsevier Inc.-USA-pp. 265-262

5- $\quad$ Alemr Brenner-(1991) Electrodepostion of Alloys V.I-New York- U.S.A- Academice press.Incpp.501

6- Arshad Husain1, Iram Javed2-(2014) Characterization and treatment of electroplating industry wastewater using Fenton's reagent-USA- Journal of Chemical and Pharmaceutical Research-pp.622-627

7- $\quad$ B. Ramesh Babu, S. Udaya Bhanu, and K. Seeni Meera- (2009) Waste Minimization in Electroplating Industries: A Review-Journal of Environmental Science and Health Part- Taylor \& Francis Group, LLC. pp.155-177.

8- Chi-Hong Liao1, Frank Ernst2, and Uziel Landau1-(2012)An Environmentally Friendly Process for Electroplating Copper on Zinc-The Electrochemical Society-USA- 


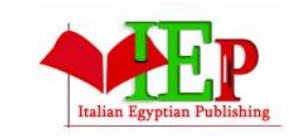

ISSN: $2735-4806$

\section{INTERNATIONAL JOURNAL OF ARTIFICIAL INTELLIGENCE AND EMERGING TECHNOLOGY}

VOLUME 1, ISSUE 1, 2018, 1 - 20.

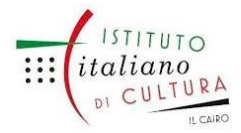

www.egyptfuture.org/ojs/

9- Dennis J. Brown, Ph.D.- (27 January 1998) Characterizing Risk at Metal Finishing FacilitiesParsons Engineering Science, Inc.- Oakland--pp.2-5

10- Dr Jaqueline Homan- Dr Steven Sadhra-(2002) Development of a methodology to design and evaluate effective risk messages Electroplating Case Study- University of Birmingham for the Health and Safety Executive .

11- Dtrijevi'c, S.; Rajci'c-Vujasinovi'c, M.; Truji'c, V.(2013) Non-cyanide electrolytes for gold plating-A review. Int. J. Electrochem. Sci.- pp. 6620-6646.

12- J.M.Mauskar-(2008) waste minimisation and ecofriendly electroplating processes-Central Pollution Control Board-India-pp.34-39

13- Leo Ronken, Gen Re, Cologne-(2019) Electroplating - Uncovering the Process, Risks and Underwriting Pitfalls-General Reinsurance AG 2019-pp.2-6

14-N.C. Rosero-Navarro, M. Curioni, Y. Castro, M. Aparicio, G.E. Thompson, -(2011)-, Glass-like Cerium containing sol-gel coatings for corrosion protection of aluminium and magnesium alloys, Surface \& Coatings Technology.pp. 206, 257,264

15-N.V. Pathasoradhy -(1989) Practical Electroplating Handbook - New Jersey U.S.A.- Prentice - Hall Inc. 16- Pascal Négré *a, Fabiola Brusciotti b, Marta Brizuela Parrab, Alicia Duránc,

17- Silvana Dimitrijević1*, M. Rajčić-Vujasinović 2, V. Trujić 1-( 2013)- Non-Cyanide Electrolytes for Gold Plating - A Review- Int. J. Electrochem. Sci., Vol. 8, pp.6627-6642

18-W. J. mclay- f. p. reinhard-(2013) waste minimization and recovery technologies- 80th universal metal finishing guidebook-metal finishing magazine- elsevier inc.-usa-pp. 317-318 19-W. J. mclay- f. p. reinhard(2014) waste minimization and recovery technologies- 80th Universal Metal Finishing Guidebook- Metal Finishing Magazine- Elsevier Inc. -USA-pp.595-614

20- Walter Giurlani 1, 2,- (2018)- Electroplating for Decorative Applications: Recent Trends in Research and Development- Coatings journal-pp.12-14.

21- Yolanda Castro Martínc, Laurence Hamond, Jacques Halute,-( 2014) Ecoprot, Eco-friendly Corrosion Protecting Coating of Aluminium and Magnesium Alloys, an ECO Innovation Project- Paris France- chemical engineering transactions- vol. 41, 2014

22- www.safeworkaustralia.gov.au 
INTERNATIONAL JOURNAL OF

ARTIFICIAL INTELLIGENCE AND EMERGING

TECHNOLOGY

ISSN: $2735-4806$

VOLUME 1, ISSUE 1, 2018, 1 - 20.

www.egyptfuture.org/ojs/

Received: February 15, 2018

Accepted: April 20, 2018 